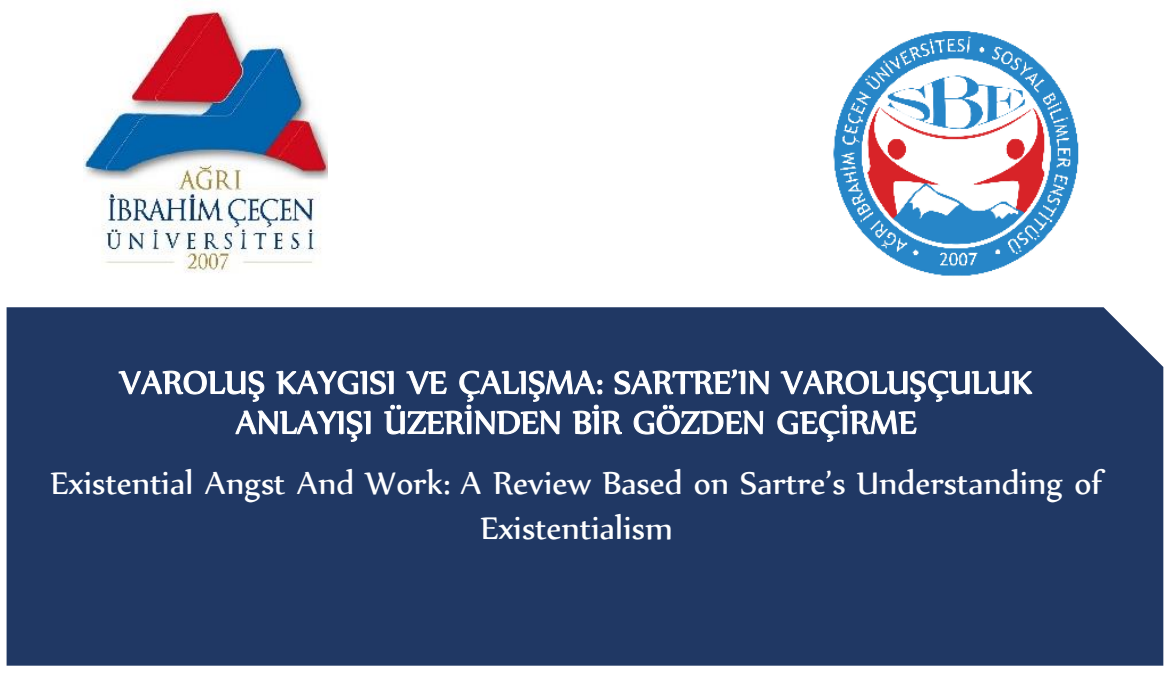

\title{
Damla AYHAN
}

Sakarya Üniversitesi iş̧letme Fakültesi

damla.ayhan92@gmail.com

iD https:/ orcid.org/0000-0002-4518-8524

Ağrı Ibrahim Çeçen Üniversitesi Sosyal Bilimler Enstitüsü DergisiJournal of Ağrı ibrahim Çeçen University Social Sciences InstituteAiCUSBED 6/2 Ekim/October 2020 / Ağrı

ISSN: 2149-3006

e-1SSN: $2149-4053$

\begin{tabular}{|l|l|}
\hline Makale Türü-Article Types $:$ & Araştırma Makalesi \\
\hline Geliş Tarihi-Received Date $:$ & 01.01 .2020 \\
\hline Kabul Tarihi-Accepted Date $:$ & 17.06 .2020 \\
\hline Sayfa-Pages $:$ 7l-77 & \\
\hline
\end{tabular}

\section{回的品}

http://dergipark.gov.tr/aicusbed

This article was checked by

$\checkmark$ iThenticate 



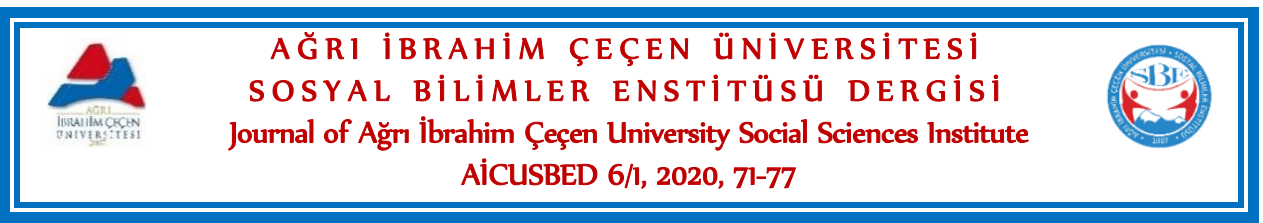

VAROLUŞ KAYGISI VE ÇALIŞMA: SARTRE'IN VAROLUŞÇULUK ANLAYIŞI ÜZERINDEN BİR GÖZDEN GEÇİRME

Existential Angst And Work: A Review Based on Sartre's Understanding of Existentialism

\section{$\ddot{O} z$}

Damla AYHAN

Araştırma da varoluş kaygısı ve çalışmanın varoluş kaygısına sunmuş olduğu katkılar incelenmektedir. İnsandaki varoluş kaygısı, yalnızlık, anlamsızlık ve özgürlüğün yarattığı gerilimler üzerinden aktarılmaktadır. Kaygıların temelinde insanın kendini anlamlandırma arayışı yattığı ve bunun kolay bir iş olmamasından dolayı da yaşamını sağlıklı devam ettirme konusunda zorlandığı vurgulanmaktadır. Bu çalışma, insanın kendine bir amaç belirleyip bu doğrultuda hareket etmesinin, kendisine, çevresine ve geleceğe faydalı olabilmesinin yöntemlerinden biri olan çalışmanın, insanların ve çalışanların varoluş kaygılarının giderilmesi yönünden varoluşçu felsefe ile incelenmesinin gerekliliğine dayanarak oluşturulmuştur. Bu çalışmada varoluşçu filozoflar içinde özellikle Jean-Paul Sartre'ın ele alınmış olmasının nedeni ise Sartre'ın bu felsefe dalını açıklamak için çaba sarf eden önemli bir düşünür olmasıdır. Giriş kısmında, varoluş̧̧uluk felsefesi, varoluş kaygısı ve çalışanların varoluş kaygısı ile çalışmayı ilişkilendirmenin gerekliliği aktarılmaya çalışılmaktadır. Sonuç kısmında, çalışanların varoluş kaygısına çözüm önerileri sunulmaktadır ve bu çalışmanın varoluş kaygısına faydaları aktarılmaktadır.

Anahtar Kelimeler: Varoluşsal kaygı, Çalışma, Anlam Arayışı, Varoluş̧̧uluk, Amaç Belirleme.

\section{Abstract}

In this research, existential angst and the contribution offered by work to this concept have been examined. The existential angst suffered by humankind has been conveyed though loneliness, meaninglessness and stress created by freedom. It has been emphasized that humankind's quest for a meaning regarding its own self is the foundation of these anxieties, since this is easier said than done, humankind suffers from difficulties when it comes to maintain their lives in a healthy manner. This research is made out of the necessity that work, as a determination of a purpose by humankind and their gravitation towards that purpose in question, is beneficial towards their own self, their environment and future had to be analyzed via the lens of existenital philosophy from the point of work itself utilized as a compensator for humankind's and employees' existential angst. The reason why this research especially focuses on Jean-Paul Sartre among existentialist philosopher is Sartre is an important thinker who put serious efort in order to explain this branch of philosophy. In the introduction, we have tried to narrate the necessity of relating existentialism, existential angst and employees' existential angst with work. In the conclusion we have provided suggestive solutions about the existential angst of employees and benefits of this research regarding existential angst.

Keywords: Existential Angst, Working, Search for Meaning, Existentialism, Purpose Determination. 


\section{GíRIŞ}

Bu makalede çalışan olmak varoluşçuluk bakış açısıyla ele alınarak yazılı doküman ve belgelerin analizi yöntemiyle incelenmiştir. Varoluş kaygısını gidermek için çalışmanın ne şekilde çözüm olabileceğinin açıklanabilmesi amaçlanmaktadır.

Çalışmaya başladığımız andan itibaren bu eylem, hayatımızın büyük bir kısmını içine almaktadır, hayatı şekillendirmekte, kimi zaman hayatın kendisi haline gelmektedir. İnsan tüm varlığını yatırdığı bu eylemin üzerine düşünmemek gibi bir yanılgıya girdiğinde kötü sonuçlar doğurabilmektedir. Kendi üzerine düşünme yetisine sahip olan insanın, hayatını ellerinin arasına alması gereken en önemli noktalardan biri de kendi çalışma yaşamı üzerinde ne derece etki edebildiği konusunda olmasi gerekmektedir. Bu da en temelde her şeyde olduğu gibi çalışmanın da bir felsefesi olduğunu fark etmekten geçmektedir.

\section{Varoluşçuluk}

Varoluş (existence) terimi Latincede "exsistere" kökünden gelmekte ve var olmak, ortaya çıkmak anlamında kullanılmaktadır (Geçtan, 2013: 30; Mendelowitz ve ark, 2012: 482). Varoluşçuluk insanın anlam arayışından yola çıkmaktadır. İnsanın kendini ve maddeyi sorgulaması sonucu yanıtlayamadığ sorulara cevap arayan varlık felsefesi olarak tanımlanmaktadır. Kierkegaard, Heidegger, Sartre, Nietzsche gibi filozoflar bu felsefenin öncülerindendir (Özakkaş, 2011: 247). Varoluşçu yaklaşım, insanı bir birim olarak ele almak yerine, ortaya çıkan, olmakta olan yani bir varlık olarak anlamaya çalışmaktadır. İnsanın yalnızca yaşadıklarını değil, yaşayan insanı da incelemektedir (May, 2012:62,117; Geçtan, 2013:30). Varoluşçu felsefenin temeli insanın varoluşunu, insanı ve insanın dünyayı algılama şeklini, anlama gayreti olarak aktarılmaktadır. Varlığını fark eden tek yaratığın insan olduğunu ve bunu fark ettiğinde nedenleri sorguladığını, varlığına anlam aradığı dile getirilmektedir (Özakkaş, 2011: 263; Çelebi, 2008: 56).

Varoluşçuluğa göre insan daha önce tanımlanamamaktadır, belirlenememektedir. Ancak sonradan bir şey olmaktadır ve kendini nasıl yaparsa öyle olacaktır. İnsan önce var olur. Kavrayacak, tasarlayacak bir başka bir şey olmadığı için insan doğası diye bir şeyden söz edilememektedir. İnsan, kendini anladığ gibi ve aynı zamanda olmak istediği olmaktadır (Sartre, 1945: 61). Bir geleceğe doğru atılan ve bu atılışın bilincine varan bir varlık olarak ortaya çıkmaktadır, öznel olarak kendini yaşayan bir tasarı olmaktadır. $\mathrm{Bu}$ tasarıdan önce anılacak kayda değer hiçbir şey bulunmamaktadır. İnsan, nasıl olmayı tasarladıysa öyle olmaya doğru yol 
almaktadır. İnsan, olmak isteyeceği şey değil, tasarlayacağı şey haline gelmektedir.

\section{Varoluşçuluk ve Çalışma}

Çalışma, insan olmanın varlık temeli ile ilgili bir olgudur ve insanın özel bir eylemi olarak tanımlanmaktadır. İnsanın, hayatın bütün alanlarında meydana getirdiği veya getirmiş olduğu başarılar, her alanda uğraştığı veya uğraşmış olduğu her şey, onun çalışan bir varlık olmasına dayanmaktadır. İnsanın hayatta kalmasını doğa üstlenmemektedir. İnsanın doğada hayatta kalmak için özel çaba sarf etmesi gerekmektedir, yaşamak için her şeyi kendisi düşünmek, kendisi meydana getirmek zorunda kalmaktadır. İnsanın yaşaması, hayatta kalması için; teknik ve sanattan, beslenme, giyinme, barınma ve korunmaya kadar birçok şeye gereksinim bulunmaktadır (Maslow, 1943: 15). Bütün bunların, insanın kendisi tarafından yaratılması, öğrenilmesi, hazırlanıp işlenmesi gerekmektedir. Fakat insanın tek başına bunun altından kalkması zor olmaktadır. İnsanın, varlığını korumak için başka insanların yardımına gereksinimi olmaktadır. Burada başka insanlar deyimi ile insanın yalnız kendi kuşağı, kendi kuşağının başarıları, deneyimleri değil, uzak veya yakın bir geçmişte yaşayan insanların, ulusların başarıları da düşünülmektedir. İnsan daha önce başka kuşaklar tarafindan gerçekleştirilen başarıları, başka kuşakların deneyimlerini devralmaktadır ve kendisi de bunları gelecek kuşaklara devretmektedir (Örnek, 1997:69)

İnsan, ne hayvan gibi günü gününe yaşar, ne de yaşayabilir, bundan dolayı insanın tek olarak yalnız kendisi için değil, başka insanlar için, hatta yakın veya uzak bir geleceğin insanları için kaygılanması, çalışması gerekir (Mengüşoğlu, 1988:167; Kuçuradi, 1980:79). İnsan, yarını, öbür günü, uzak zamanları düşünmek; gelecek zamanlar için önceden önlem almak, kendisinin hayatta kalmasını sağlayan, devraldığı başarıları sürdürmek zorundadır. $\mathrm{Bu}$, insana ödevler, sorumluluklar yükler. İnsanın bugünkü başarılarının sürekli bir çalışma ile oluştuğu düşünülürse, çalışmanın önemi daha iyi anlaşılabilmektedir. Çalışma, yalın bir olay olarak ele alınmamaktadır; karmaşık, çok öğeli bir örgü olarak açıklanmaktadır. İnsanın, çalışabilmek için, çeşitli teknikleri öğrenmesi, araçlar arayıp bulması gerekmektedir (Navaro, 2014:26).

Sartre'a göre, varoluşun özden önceliği anlayışı, insanın bir öz ve doğa üzere dünyaya geldiği görüşünü tümüyle yadsır. Özsüz, doğasız ve yazgısız kalan kişi ne olduğuna, kim olduğuna, nereye gideceğine, kim olacağına kendisi karar vermek, böylece kendi varoluş değerini yaratmak zorundadır (Erhat, 1964:35; Sartre, 1945:54). Varoluşçuluğun temelinde

http://dergipark.gov.tr/aicusbed 6/2 Ekim / October 2020 
insanın kendini anlamlandırma çabası ve anlamlandırabildiği ölçüde insanlaşabildiği düşüncesi yatmaktadır. Kendini inşa etme durumunda olan insan, bunu yaşamında sürekli eylemde bulunarak yapacaktır (Sartre, 1946:71). İnsanın kendini anlamlandırma çabasını gerçekleştirebilmek için, aktif bir şekilde ürün ortaya çıkarabildiği bir alan bularak meslek sahibi olması gerekmektedir (Navaro, 2014:52).

\section{Çalışanların Varoluş Kaygısı}

Varoluş̧̧ulukta, insan her şeyden önce, kendisini manasız bir varlık ve beyhude bir hayat karşısında bulmaktadır. Bu durum ile karşı karşıya gelme, insanda bir irkilme ve tiksinme hali vücuda getirmektedir, Sartre, buna "bulantı" adı vermektedir İnsan, bir yandan varlığın bütün ağırlığını kendi omuzlarında hissetmektedir diğer yandan da onun bir saçmalıktan ibaret olduğunu kavramaktadır. $\mathrm{Bu}$, insan için bir varoluşsal sıkıntı halini almaktadır. Anlamsız ve yetersiz hisseden kendisini temellendiremeyen insan, kendisini tedirginlik içinde bulmaktadır (Ritter, 1954:13).

İnsanda varoluşsal gerilime sebep olan kavramlardan biri özgürlük olarak tanımlanmaktadır (Yalom, 2014:337; Mendelowitz, 2012:475; Tokat, 2013:96). Özgürlük, olumlu bir kavram olarak düşünülmesinin yanı sıra insanın kendi seçimlerinden sorumlu olması anlamına gelmektedir ve bu anlamda özgürlüğün korkutucu olduğu düşünülmektedir. Sorumluluk, varoluşçulukta özgürlükle yakından ilişkili bir kavram olarak yer almaktadır (Yalom, 2014:345; Mendelowitz 2012:475). Varoluşsal anlamda sorumluluk, insanın kendi hayatının, duygularının farkında olması olarak tanımlanmaktadır Birey kendi dünyasını oluşturacak kadar sorumluluğu almadığı sürece dünyanın bir anlamı olmadığı belirtilmektedir (Yalom, 2014: 345). İnsan sorumludur denildiği zaman, yalnızca kendinden sorumlu olduğu anlamına gelmemektir, bütün insanlardan sorumlu olduğu anlatılmaya çalışılmaktadır. Öznelcilik sözcüğünün çifte anlamlılık üzerinde bakıldığında, öznelcilik, bir yandan bireysel öznenin kendi kendini seçmesi, öbür yandan da insancıl öznelliği aşmanın kişinin elinde olmaması anlamına gelmektedir. Varoluşçuluğun derin anlamı bunlardan ikincisinde gizlenmektedir. İnsan kendi kendini seçer, bu her birimizin kendi kendini seçmesi demektir. Ama insan kendini seçerken bütün insanları da seçmiş olmaktadır. İnsanın, kendini seçmesi aynı zamanda bütün öbür insanları da seçmesi anlamına gelmektedir. İnsan, olmak istediği kimseyi yaratırken, herkesin nasıl olması gerektiği de tasarlamaktadır Her bir edim, olmasını zorunlu saydığımız bir insan tasarımı doğurmaktadır. Şöyle ya da böyle olmayı seçmek, bir bakıma, seçtiğimiz şeyin değerli olduğunu belirtmek demektir. Bireysel edimler bütün insanlığı 
bağlamaktadır. Kişi kendine karşı sorumlu olunca, herkese karşı da sorumlu olmuş olmaktadır. Seçilen belirli bir insan tasarısı kurulmaktadır, yani insan kendini seçerken gerçekte insanı seçmiş olduğu anlamına gelmektedir (Sartre, 1943:35). Çalışanlar kendi sorumluluklarını almanın yanı sıra hizmet verdikleri bireylerin sorumluluklarını da üstlenmektedirler (Engin, 2016:43). $\mathrm{Bu}$ sorumluluğu alırken iyi bir hizmet verebilmek için, çalışan kişi öncelikle kendini tanımalı, duygularının ve seçimlerinin farkında olmalıdır. Aynı zamanda hizmet verdikleri ve birlikte çalıştıkları bireylerin kendi sorumluluklarını almaları konusunda onları desteklemeleri gerekmektedir.

İnsanlarda varoluşsal gerilime sebep olan bir diğer kavram soyutlanma olarak tanımlanmaktadır. Varoluşsal soyutlanma insanın kendisi ile diğer kişiler arasındaki kapanmayan boşluğu ifade etmektedir. İnsan hem diğerinin parçası olmak hem de ayrılmak isteyerek bu varoluşsal çatışmayı yaşar. (Yalom 2014:553,554,556,563; Geçtan, 2013:43; Mendelowitz 2012:476). İnsanın derin ve anlamlı bir şekilde bağlanabilmesi için, kalabalığa girip kendine yabancılaşmak yerine, yalnızlıkla yüzleşmesi gerekmektedir. İnsan bunu kabul ettiği zaman sevgiye yönelmektedir (Yalom, 2014:565; Geçtan 2013:141). Etkileşim, gerçekçilik, duygudaşlık ve olumlu koşulsuz kabullenme üzerine kurulu ilişkilerde varoluşsal soyutlanma daha az hissedilmektedir. Çalışanların kendi varoluşsal yalnızlıklarının farkında olmaları, hizmet ettikleri ve birlikte çalıştıkları bireylerin yalnızlığını göz ardı etmemeleri gerekmektedir. Çalışma ortamında, cinsiyeti, memleketi, dili, dini, görünüşleri ve görüşleri birbirinden farklı birçok insan ile etkileşime girerek ve sağlıklı ilişkiler kurarak varoluşun yalnızlık veya soyutlanma kaygısını çözüme kavuşturması gerekmektedir.

İnsanlarda varoluşsal gerilime sebep olan bir diğer kavram anlamsızlık olarak tanımlanmaktadır. Bilinçli olduğu kadar duygulu da bir varlık olan insanın, hayatına bir anlam bulmaya ihtiyacı bulunmaktadır. İnsanın, kendi özünü kendi özelliklerine uygun bir biçimde gerçekleştirmiş bir birey olabilmesi için, anlam sorununun doğurduğu ihtiyacı da tatmin edici bulduğu cevaplarla karşılamış olması gerekmektedir (Yaran, 2001:79). İnsanlar kendi dünyalarını yaratırken neden ve nasıl yaşadıklarını, nasıl yaşamak istediklerinin cevaplarını bilmek istemektedir (Yalom, 2014:649; Mendelowitz, 2012:478). İnsanın ne istediğini algılayamadığında, yaşadığı boşluk, kendisini güçsüz hissetmesine ve kendi yaşamının kontrolünün kendi ellerinde olmadığı hissine sebep olmaktadır (Geçtan 2013:139). Çalışan insanlar bir amaç belirleyip bu amaç doğrultusunda hareket etmelidirler. İnsan amacını çalışma yaşamında gerçekleştirdiği zaman kendisine, çevresine ve

http://dergipark.gov.tr/aicusbed 6/2 Ekim / October 2020 
geleceğe faydalı olacaktır. Dahası yaşamından doğan gerilimi de çözüme kavuşturacaktır.

\section{SONUC}

Varoluşçuluk açısından çalışanlar da varoluşlarını sorgulamaktadır. Ancak varoluşları gereği meydana getirdiği üretim, yenilik ve daha anlamlı mesleki çalışmaları gerçekleştirebilmek için üzerlerine düşen sorumluluklarını göz ardı ettikleri düşünülmektedir. Çalışanların varoluşu için, bütün çalışanlar, iş birliği içerisinde olması gerekmektedir. Çalışanların var olan bilgiyi tekrarlamak yerine, kendi varoluş değerlerini üretirlerse bu durum varoluşlarına katkı sağlayacağı düşünülmektedir.

Çalışanların hizmet verdiği kişilerin sorumluluğunu alabilmesi için öncelikle kendi sorumluluklarını alabilecek bireyler olması gerekir. Diğer yandan çalışanların, var oluşuna bir tehdit olarak ortaya çıkan, varoluş kaygılarını anlamak ve çözüme kavuşturmak önemli olmaktadır.

Hayatın bir anlam ve amacının olduğu ve insanın kendi anlam ve amacını kendisinin yaratması gerektiğini bilmesi ve varoluş kaygısının yarattığı gerilimleri en aza indirmenin mümkün olduğunu bilmesi kişiyi ruhsal ve dolayısıyla bedensel problemlere karşı korumaktadır. Karşılaşılan küçük sıkıntılardan büyük felaketlere kadar pek çok şeyin aslında kendi anlamını yaratması açısından birer kapı olduğunu bilmek kaygı azaltıcı bir unsur olabilmektedir.

\section{KAYNAKÇA}

Çelebi, V. (2008). S. Kierkegaard ve J. P. Sartre'ın Varoluşçuluk Anlayışlarının Karşılaştırılması. Yayımlanmamış Yüksek Lisans Tezi, Denizli: Pamukkale Üniversitesi Sosyal Bilimler Enstitüsü.

Engin, E. (2016). 'Türkiye'de Hemşire Olma Kaygısı: Varoluş̧̧u Felsefe Bakış Açısıyla Bir Gözden Geçirme." Uluslararası Sosyal Araştırmalar Dergisi, 9:43.

Erhat, A. (1964).' Sartre'ın Sözcükleri.' Yaşamak Dergisi, Ekim sayısı.

Geçtan, E. (2013). Varoluş ve Psikiyatri. 8. Baskı, İstanbul: Metis Yayınları.

Maslow, A. H. (1954). Personality and Motivation. Harlow, England: Longman.

May, R. (2012). Varoluşun Keşfi. çev., Erte, Ö, İstanbul: Okuyan Us (Orijinal çalışma basım tarihi 1983).

Mendelowitz, E, Schneider, K, Yalom, I. (2012). Varoluşçu Psikoterapi. İçinde: (Darcan S., Çeviri editörü). Modern Psikoterapiler, İstanbul: Kaknüs Yayınları (Orijinal çalışma basım tarihi 2011).

Mengüşoğlu, T. (2016). İnsan Felsefesi. Doğu Batı Yayınları. 
Navaro, D. (2014). Kariyer ve Varoluş: Bir Benlik Eylemi. Ankara: Elma Yayınevi.

Örnek, Y. (1997). Felsefede Antropoloji Geleneği ve Takiyettin Mengüşoğlu, Yüzyılımızda İnsan Felsefesi-Takiyettin Mengüşoğlu Anısına. Ankara: Türkiye Felsefe Kurumu Yayınları: 69-82.

Özakkaş, T. (2011). Varoluşçu Psikoterapi. ed., Takçı H, Bütüncül psikoterapi. İstanbul: Litera Yayıncılık.

Ritter, J. (1954). Varoluş Felsefesi Üzerine. çev., Batuhan, H, İstanbul Üniversitesi Edebiyat Fakültesi Yayınları.

Sartre, J. P. (2017). Bulantı. çev. Hilav, S, İstanbul: Can Yayınları (Orijinal çalışma basım tarihi 1938).

Sartre, J. P.. (2014) Varlık ve Hiçlik. çev., Ilgaz, T, Çankaya, G, İstanbul: İthaki Yayınları (Orijinal çalışma basım tarihi 1943).

Sartre, J. P.. (2015) Varoluşçuluk. çev., Bezirci, A, İstanbul: Say Yayınları (Orijinal çalışma basım tarihi 1946).

Yalom, I. D. (2014). Varoluşçu Psikoterapi. çev., Babayiğit, Z. İ, İstanbul: Kabalcı Yayıncılık. (Orijinal çalışma basım tarihi 1980).

Yaran, C. (2001). "İnsanın Egzistansiyal İhtiyaçları ve Dinin Perenniyal Cevaplar1.’' Ondokuz Mayıs Üniversitesi İlahiyat Fakültesi Dergisi, 12 (12-13), 79-96. 